\title{
Pitting Behavior of Aluminum Foil during Alternating Current Etching in Hydrochloric Acid Containing Sulfate Ions
}

\author{
C. S. Lin ${ }^{*, z}$ and W. J. Li
}

Department of Materials Science and Engineering, National Taiwan University, Taipei, Taiwan

Sulfate ions in sodium chloride solutions effectively enhance the capacitance of aluminum foils etched with direct current. This study explored the effects of sulfate ions on pitting behavior of aluminum foils for low-voltage electrolytic capacitor during etching with alternating current. Experimental results indicate that the presence of sulfate ions in hydrochloric acid reduced the loss of aluminum due to undermining by the cubic pits. Furthermore, sulfate ions adsorbed on the aluminum surface increased the breakdown potential of the surface film and led to passivation of the existing pits. Consequently, the aluminum foil etched in the solution with the addition of sulfate ions displayed a more uniform pitted structure than that etched in the solution solely composed of hydrochloric acid.

(C) 2005 The Electrochemical Society. [DOI: 10.1149/1.2131830] All rights reserved.

Manuscript submitted April 6, 2005; revised manuscript received September 12, 2005. Available electronically December 2, 2005.

Aluminum foils for low-voltage electrolytic capacitors are generally etched in hydrochloric acid with alternating current, ${ }^{1-6}$ in which the pits that form during the anodic half-cycle are passive during the subsequent cathodic half-cycle by the precipitation of the etch film. ${ }^{1,2}$ This results in a cauliflower-like pitted structure on both sides of the foil, leaving the central core unetched. ${ }^{3,4}$ The capacitance of the foil is closely related to its pitted structure, which is controlled by the nucleation, growth, coalescence, and propagation of the pits. Such pitting behavior is strongly influenced by the waveform of the alternating current ${ }^{4,5}(\mathrm{ac})$, the composition of the electrolyte, and the additives such as aluminum ions, transition metal compounds, phosphates, sulfates, tartrates, and oxalates, ${ }^{6-9}$ bath temperature and $\mathrm{pH}, 4,5$ as well as factors related to the purity and microstructure of the foil including grain structure, defects and textures, and type and amount of the various precipitates. ${ }^{10,11}$

Sulfate ions in sodium chloride solutions have been shown to enhance the capacitance of aluminum foils etched with the direct current $(\mathrm{dc})$ via refinement of etch configuration and the increase in the population density of the tunnel pits. ${ }^{12-14}$ The presence of sulfate ions also causes a shift of the breakdown potential in the noble direction $^{14-16}$ and an increase in the induction time for the onset of pitting of aluminum during anodic polarization in chloridecontaining solutions. ${ }^{16,17}$ Competitive adsorption ${ }^{14-16,18}$ of sulfate ions with chloride ions and the formation of aluminum sulfate ${ }^{14}$ have been proposed to explain the effects of sulfate ions on the pitting behavior of aluminum. The competitive adsorption mechanism stems from the fact that sulfate ions are a potential corrosion inhibitor, ${ }^{16,19,20}$ while chloride ions are an aggressive species inducing pitting on most of aluminum alloys. ${ }^{16,21}$ A model has been well established to explain the pitting corrosion of aluminum in chloridecontaining solutions, and involves sequentially adsorption of chloride ions on the oxide surface, penetration of chloride ions through the oxide film by migration through oxygen vacancies or by oxidation film dissolution, and localized dissolution of aluminum at the metal/oxide interface. ${ }^{21}$ Although sulfate ions markedly affect the pitted structure of aluminum during dc etching, their effects on the pitting behavior of aluminum subjected to ac etching are less well studied. This study details the effects of sulfate ions in hydrochloric acid on the nucleation and propagation of the pits on aluminum foils during ac etching. The microstructure of the etch films is also characterized in detail.

\section{Experimental}

AC etching. - The material used for this study is the commercial aluminum foil (99.985 wt. \% purity) for low-voltage electrolytic capacitors. Prior to etching, the foil was cleaned in a solution com-

* Electrochemical Society Active Member.

z E-mail: csclin@ntu.edu.tw posed of $20 \mathrm{~mL} \mathrm{~L}^{-1}$ nitric acid and $20 \mathrm{~g} \mathrm{~L}^{-1}$ sodium sulfate at $75^{\circ} \mathrm{C}$ for $2.5 \mathrm{~min}$ and then thoroughly rinsed in deionized water. AC etching was carried out in $0.8 \mathrm{M}$ hydrochloric acid without and with addition of 0.005 or $0.02 \mathrm{M}$ sodium sulfate at $35^{\circ} \mathrm{C}$ using $25 \mathrm{~Hz}$ triangular waveforms with a peak current density of $38 \mathrm{~A} \mathrm{dm}^{-2}$. The exposure area of the foil was $2 \times 6 \mathrm{~cm}$, and a high-density graphite plate of $120 \times 38 \mathrm{~cm}$ was used as the counter electrode. A saturated calomel electrode (SCE) was employed as the reference electrode. After etching, the foil was rinsed in deionized water and dried in room temperature air overnight. Some of the foils were immersed in a mixture of $0.2 \mathrm{M}$ chromic and $0.55 \mathrm{M}$ phosphoric acid to remove the etch products formed during etching. The mass difference of the foil before etching, and after removal of the etch product was defined as the weight loss of the foil during etching, and was reported as an average of three specimens separately etched in the same condition.

Current vs potential curves.- During the course of etching, the potential with reference to SCE and the current were recorded synchronously. The galvanodynamic polarization curve was then plotted, in which the breakdown potential was measured. ${ }^{4-7}$ That is, during the anodic half-cycle, the potential went through a maximum while the current kept increasing. This peak potential represented the breakdown potential associated with the surface film on the foil.

Microstructural characterization.- After removal of the etch products, the surface morphology of the foil was investigated using scanning electron microscopy (SEM). Cross-sectional SEM specimens were prepared from the as-etched foil for characterizing the overall pitted structure. Cross-sectional transmission electron microscope (TEM) specimens were also prepared from the as-etched foil to reveal the detailed pit morphology and etch film structure. Additionally, the composition of the etch film was measured via energydispersive spectrometry (EDS) in TEM using an electron probe $10 \mathrm{~nm}$ in diameter, and the structure of the etch film was identified using the electron diffraction technique. Finally, X-ray photoelectron spectra of the surface film on the as-etched foil were measured using an ESCA250 (VG Science Inc., U.K.) spectrometer with monochromatic $\mathrm{Mg} \mathrm{K} \alpha$ radiation. The pressure in the spectrometer was approximately $10^{-9}$ Torr during the measurements. Binding energy of the peak was referenced to the $\mathrm{C} 1 \mathrm{~s}$ peak at $285 \mathrm{eV}$.

\section{Results}

Surface morphology and cross-sectional characterizations.Figure 1 shows the surface morphology of the foil after etching in the various solutions for 100,500 , and 1500 cycles, respectively. The foil was dotted with numerous pits after 100 cycles of etching. Up to this stage of etching, no distinct difference was observed for the specimens etched in the solutions with and without sulfate ions (Fig. 1a-c). As etching proceeded to 500 cycles, most of the pits had grown to a larger size by the merge of several individual 


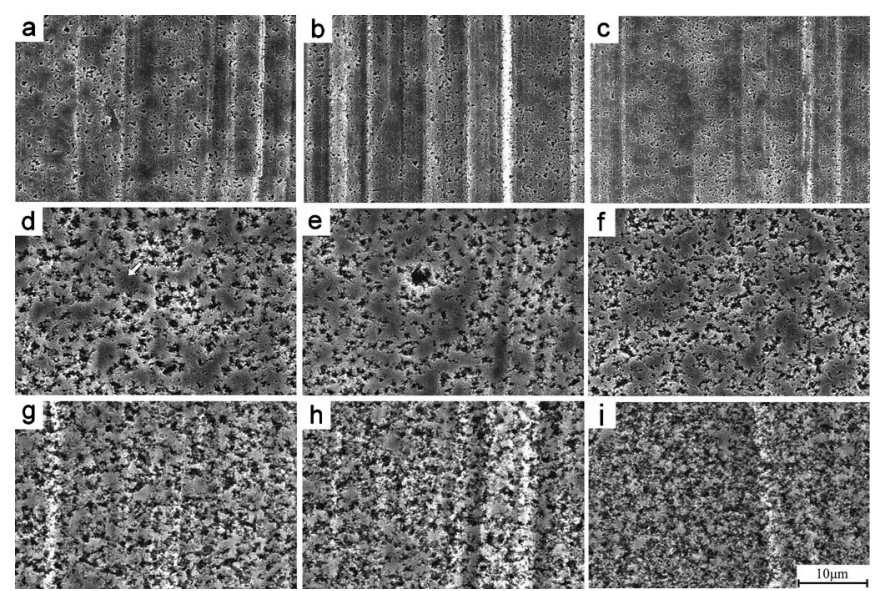

Figure 1. Surface morphology of the foil after etching in $0.8 \mathrm{M}$ hydrochloric acid for (a) 100; (d) 500; and (g) 1500 cycles; in $0.8 \mathrm{M}$ hydrochloric acid with $0.005 \mathrm{M}$ sodium sulfate for (b) 100; (e) 500; and (h) 1500 cycles; and in $0.8 \mathrm{M}$ hydrochloric acid with $0.02 \mathrm{M}$ sodium sulfate for (c) 100; (f) 500; and (i) 1500 cycles.

pits while some areas of the foil remained relatively flat, on which scattered fine pits were observed (see the arrow in Fig. 1d). Compared with the other two samples, the foil etched in the solution with $0.02 \mathrm{M}$ sulfate ions contained smaller pits and fewer flat areas. This difference continued up to the maximum number of cycles studied, i.e., 1500 cycles when the foil was uniformly and almost completely attacked in the solution with $0.02 \mathrm{M}$ sulfate ions, as shown in Fig. 1i.

Figure 2 shows the cross-sectional TEM micrographs of a foil after etching in $0.8 \mathrm{M}$ hydrochloric acid for 500 cycles. Crosssectionally observed in TEM, the foil without etching exhibited a laminated structure in which the aluminum grains had been deformed and elongated along the rolling direction and contained high-density dislocations and subgrains, a characteristic of the hard aluminum foil for low-voltage electrolytic capacitors (Fig. 2a). Figure $2 b$ shows the overall pitted structure of the foil. Figure $2 c$ further reveals that the cubic pit was the basic building element of the pitted structure, in good consistence with those observed on aluminum etched in hydrochloric acid with the ac current. ${ }^{2,3,6,22-24}$ The merge of the fine cubic pits resulted in two overall pitted morphologies: V-shaped and U-shaped relatively large pitted structure, as depicted by the solid lines in Fig. 2b. Furthermore, the unattacked aluminum (marked by the arrow in Fig. 2b) was frequently observed on the surface of the foil, and would peel from the foil when further undermining of the cubic pits occurred with continued etching. Figure $2 \mathrm{c}$ shows that the unattacked aluminum overhanging on the mouth of the relatively large pit was generally encompassed by strings of cubic pits (the arrow in Fig. 2c). The complete coalescence of these strings would eventually cause the loss of the unattacked aluminum.

Figure 3a shows that the foil etched in hydrochloric acid with addition of $0.02 \mathrm{M}$ sulfate ions also contained cubic pits, which, once coalesced, resulted in either the V-shaped structure or the U-shaped structure. Compared with the foil etched in $0.8 \mathrm{M}$ hydrochloric acid, the presence of sulfate ions in the solution suppressed the formation of strings of cubic pits, thus promoting the formation of U-shaped structure. The U-shaped structure contained less unattacked aluminum than the V-shaped structure. Figure $3 \mathrm{~b}$ is a closeup view of the area inside a U-shaped structure. It is shown that the walls of the cubit pit were covered with etch products (marked by the arrow). Furthermore, these etch products were amorphous, as evidenced by the inset nanobeam electron diffraction pattern in Fig. $3 \mathrm{a}$. Because the etch product was amorphous, it was easier to differentiate the boundary between the etch product and aluminum by titling the specimen so that the aluminum substrate underwent
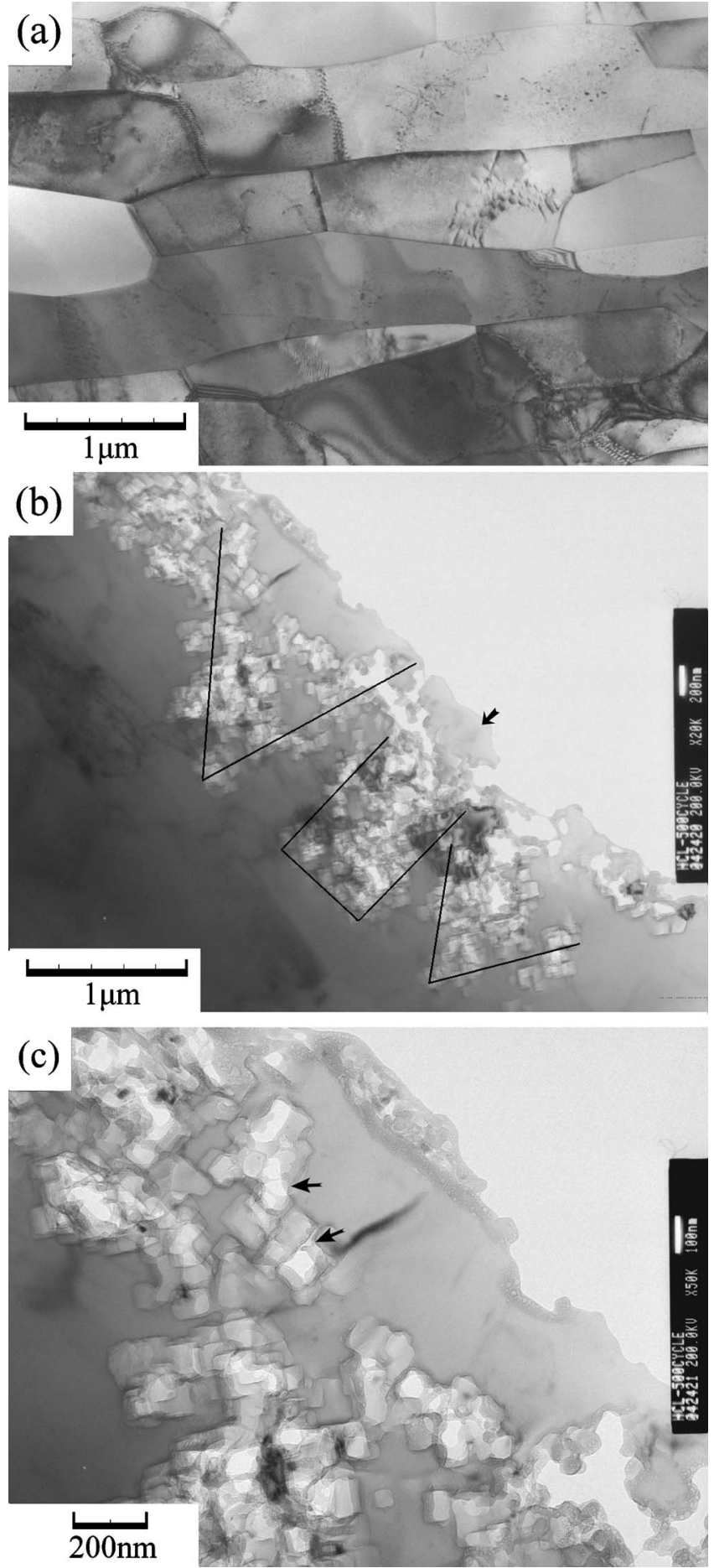

Figure 2. Cross-sectional TEM micrographs of the foil after 500 cycles of etching in $0.8 \mathrm{M}$ hydrochloric acid: (a) the overall microstructure of the unetched foil; (b) the overall pitted structure; and (c) the unattacked aluminum encompassed by strings of cubic pits.

strong diffraction relative to the electron beam. Under this condition, some aluminum grains exhibited a relatively dark contrast (marked by " 3 " in Fig. 3b) and two types of the etch products were observed the porous overlay and the layer directly contacting aluminum, which are marked as " 1 " and "2" in Fig. 3b, respectively. Figure 3c shows that the EDS spectrum from the porous overlay contained aluminum, oxygen, and traces of sulfur and chloride species. Sulfate and chloride anions were apparently adsorbed and incorporated into 


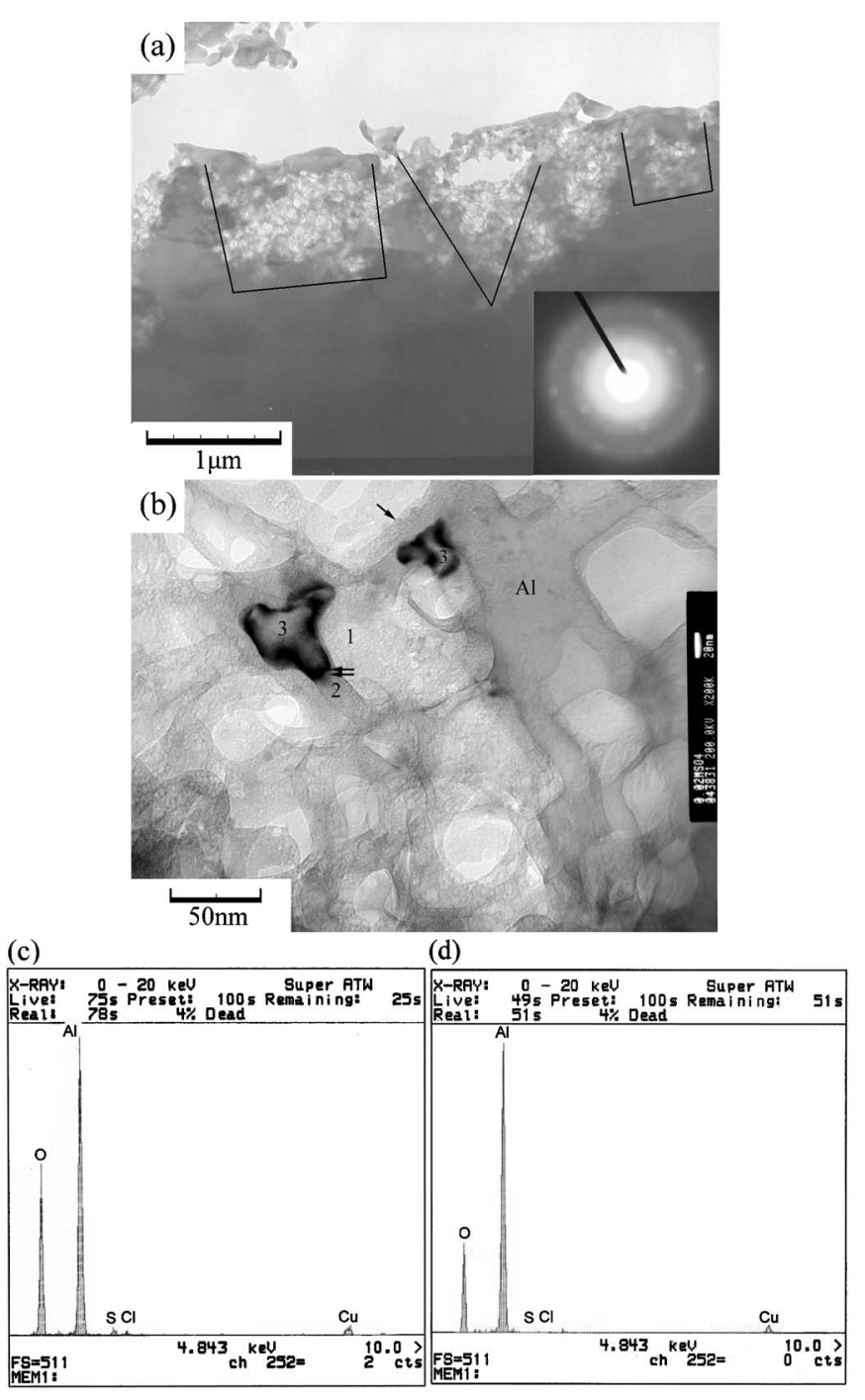

Figure 3. Cross-sectional TEM characterization of the foil after 500 cycles of etching in $0.8 \mathrm{M}$ hydrochloric acid with $0.02 \mathrm{M}$ sodium sulfate: (a) the overall pitted structure; (b) a close-up view of the pitted structure and etch film; and (c) and (d) the EDS spectra taken from the area marked as 1 and 2 in (b). Inset in (a) is the nanobeam electron diffraction pattern taken from the porous layer with an electron probe $25 \mathrm{~nm}$ in diameter.

the porous layer during etching. Aluminum etched in hydrochloric or nitric acids using the ac current is generally covered with etch films that are composed of hydrated aluminum oxide. ${ }^{1,2,22-24}$ The porous overlay observed in the present study is thus presumably aluminum hydroxide. The spectrum taken from the layer (marked as "2" in Fig. 3b) directly contacting aluminum also contained aluminum and oxygen; however, the sulfur and chloride signals were below the detection limit of EDS as shown in Fig. 3d. A clear and continuous boundary between this layer and aluminum, as indicated by the double arrow, can also be seen in Fig. 3b. Therefore, the layer directly contacting the substrate is likely a result of anodization of aluminum in the solution during the anodic half-cycle, ${ }^{7}$ while the porous aluminum hydroxide resulted from $\mathrm{Al}(\mathrm{OH})_{4}^{-}$colloid due to $\mathrm{pH}$ rise during the cathodic half-cycle. ${ }^{1,2,22-24}$

To statistically compare the effect of sulfate ions on the population density of V- and U-shaped pitted structure, and on the average depth of the pitted structure, cross-sectional SEM micrographs were taken at a magnification of 2500. Like cross-sectional TEM characterization, V- and U-shaped structure were also observed on crosssectional SEM specimens, as marked by "V" and "U" in Fig. 4a,
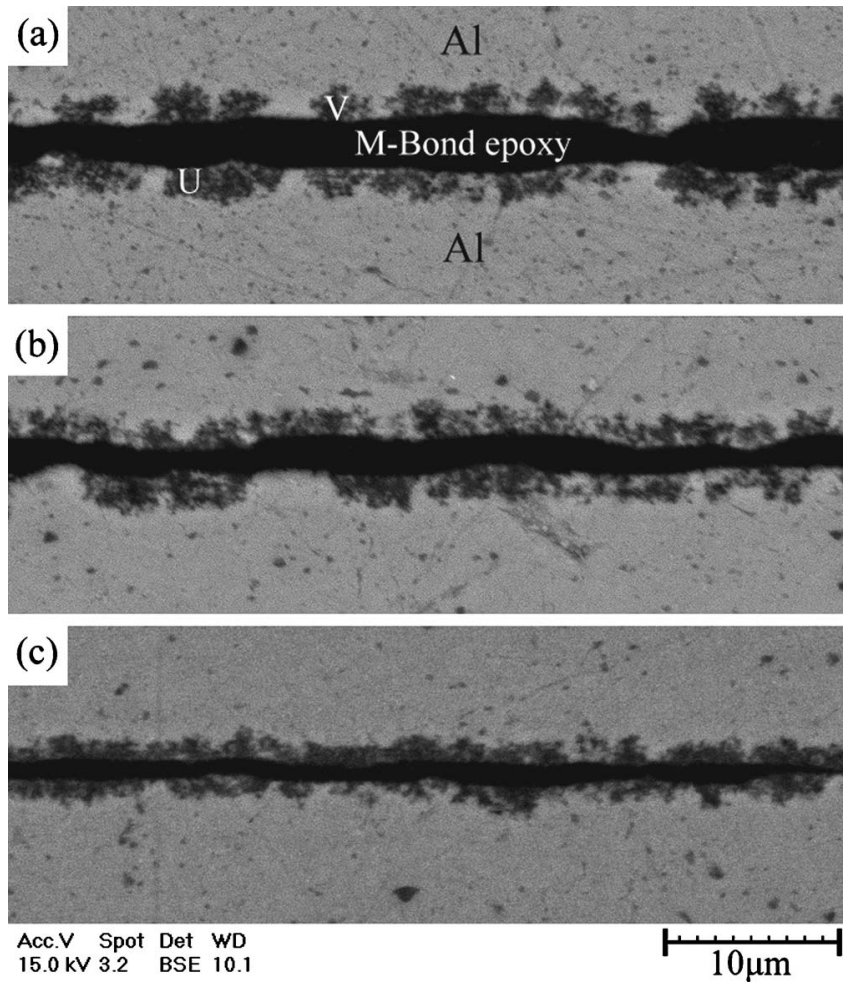

Figure 4. Cross-sectional SEM micrographs of the foil after 500 cycles of etching in $0.8 \mathrm{M}$ hydrochloric acid (a) without; and (b) and (c) with addition of 0.005 and $0.02 \mathrm{M}$ sodium sulfate, respectively.

respectively. The linear density of $\mathrm{V}$ - and U-shaped structure and the average depth of these structures were then measured on ten SEM micrographs taken randomly on each specimen. Theses measurements show that the linear density of the U-shaped structure increased, while that of the V-shaped structure decreased as sulfate ions were added to the solution (Fig. 5a). Moreover, both the V- to U-shaped structure ratio and the average depth decreased with increasing solution sulfate ion concentration (Fig. 5b)

Weight loss.-Figure 6 shows the weight loss as a function of the number of ac cycles. The presence of sulfate ions in hydrochloric acid reduced the weight loss of the foil. This reduction became more pronounced as etching continued. The difference in the weight loss of the foil etched in the solution with and without sulfate ions is partly due to the loss of the unattacked aluminum, because undermining of aluminum by strings of cubic pits became more severe with continued etching. The weight loss increased slightly as the concentration of sulfate ions was increased from 0.005 to $0.02 \mathrm{M}$. This increase is probably due to the enhancement of the growth of the pits and the formation of tunnels from the pits. ${ }^{14}$

Galvanodynamic polarization curves. - Figure 7a-c shows the galvanodynamic polarization curves of the foils etched in the various solutions at 100, 500, and 1500 cycles, respectively. An obvious breakdown potential $\left(E_{b}\right.$ in Fig. $7 \mathrm{a}$ ) was noted in $0.8 \mathrm{M}$ hydrochloric acid without sulfate ions, after which the potential decreased while the current increased as etching continued. In contrast, in the presence of sulfate ions a rather constant potential was observed after the breakdown of the etch film. This indicates that some of the newly nucleated pits formed upon the breakdown of the film were passivated as the anodic half-cycle continued. This passivation can be due to adsorption of sulfate ions or repair of the etch film by sulfate ions. ${ }^{18}$ Figure 7 also shows that repassivation of the pit depends on the concentration of sulfate ions in the solution. After 500 cycles of etching, the galvanodynamic polarization curve measured in the solution with $0.005 \mathrm{M}$ sulfate ions resembled that in the 
(a)
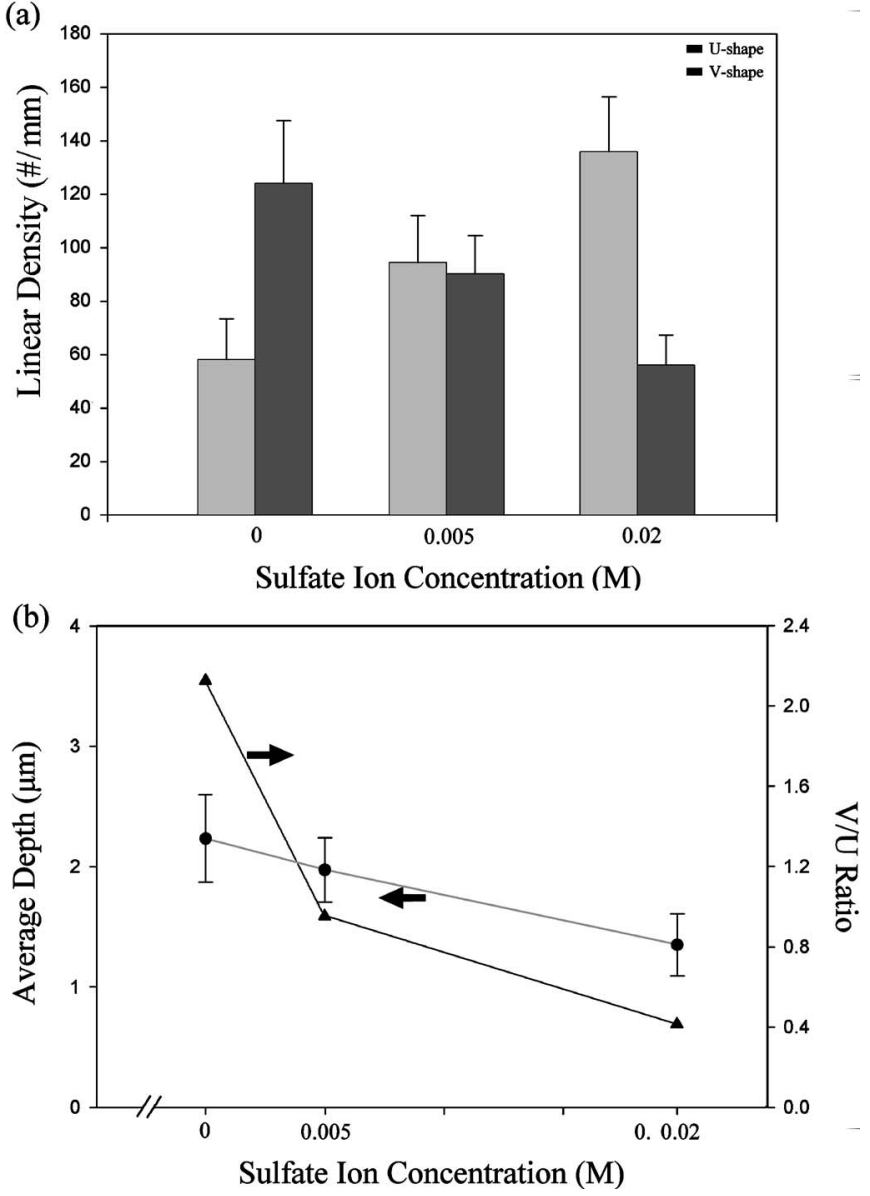

Figure 5. Effect of sulfate ions on (a) the linear density of V-shaped and U-shaped structure, and (b) the average depth of the pitted structure and the ratio of $\mathrm{V}$ - to U-shaped structure.

solution without sulfate ions, on which the potential decreased while the current increased after the breakdown potential had been reached (Fig. 7b). On the contrary, in the solution with $0.02 \mathrm{M}$ sulfate ions the potential above the breakdown potential was still a constant and a maximum anodic potential response in phase with the current still existed after 1500 cycles of etching (Fig. 7c).

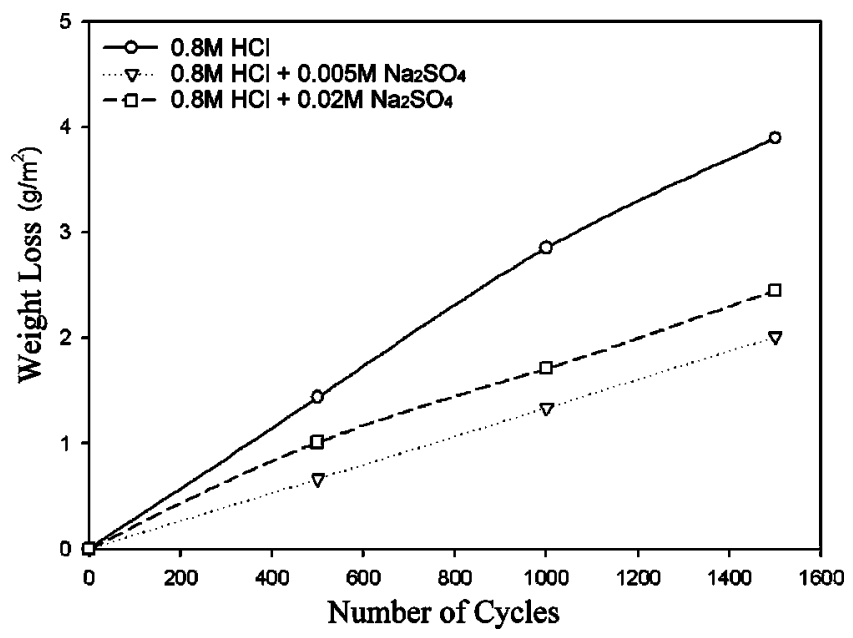

Figure 6. Weight loss of the foil as a function of the number of etching cycles.
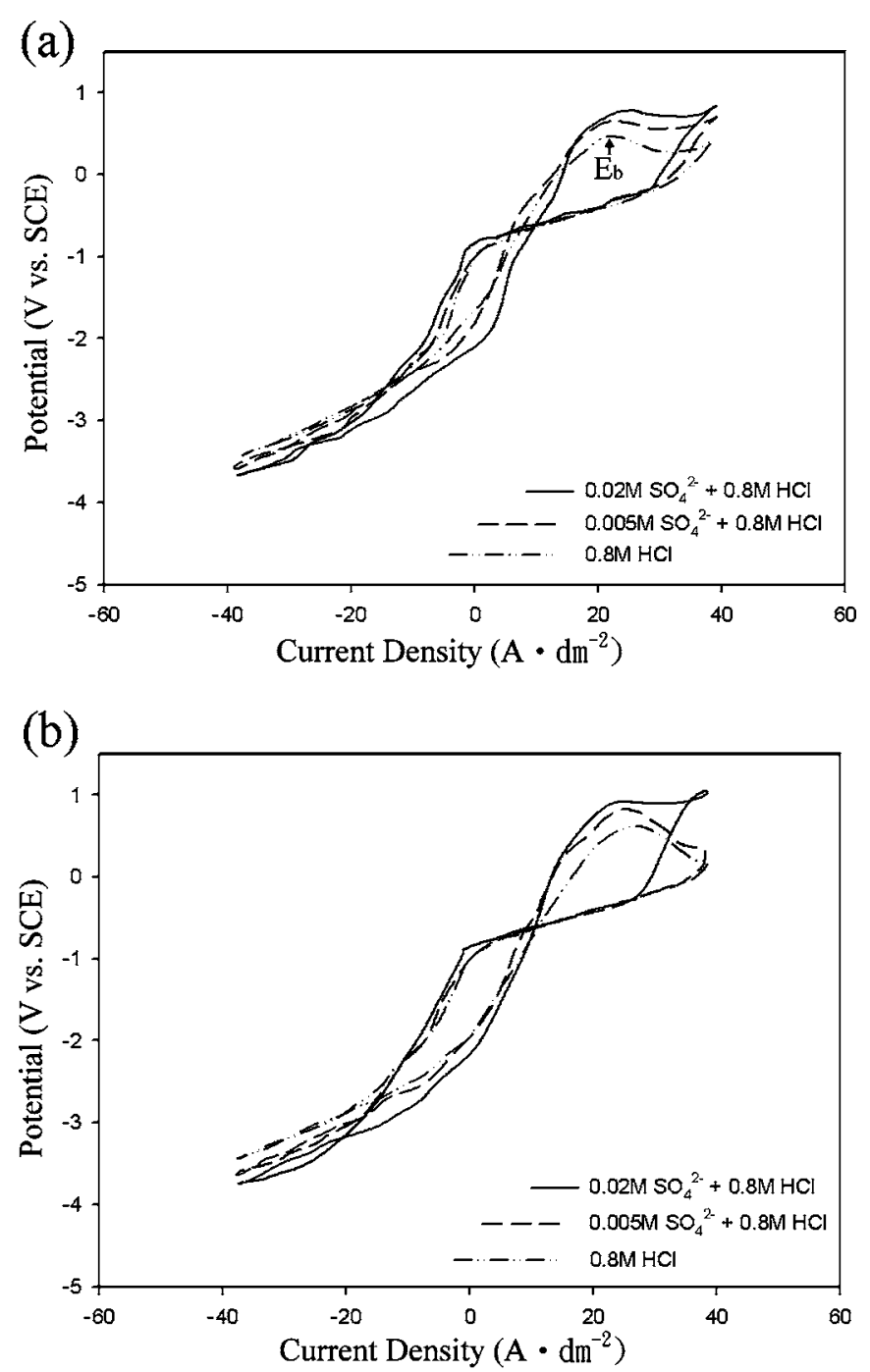

(c)

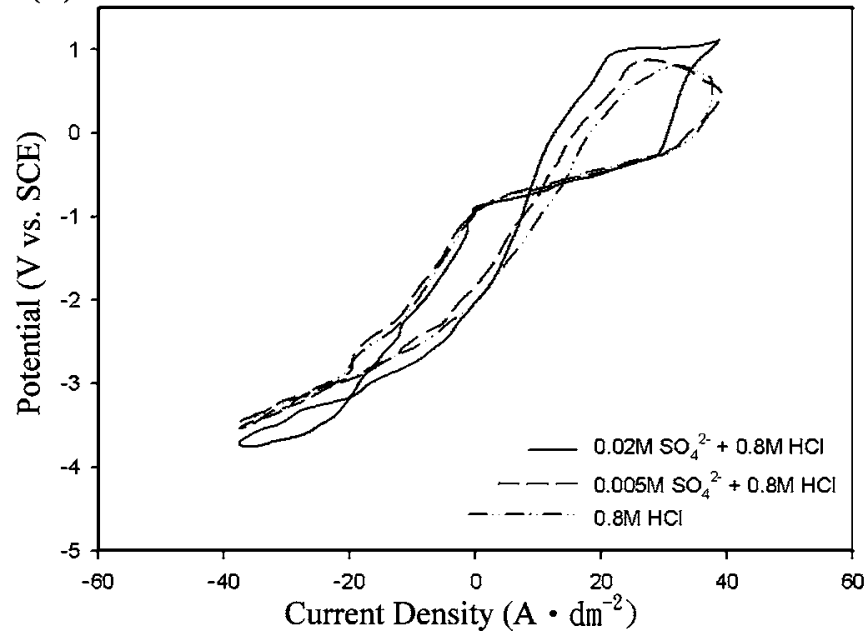

Figure 7. Galvanodynamic polarization curves of the foil after etching in the various solutions at (a) 100; (b) 500; and (c) 1500 cycles, respectively.

Figure 8 shows the dependence of the breakdown potential on the number of etching cycles. The breakdown potential generally increased with continued etching regardless of the solutions, and would gradually reach a constant value. Furthermore, the breakdown 


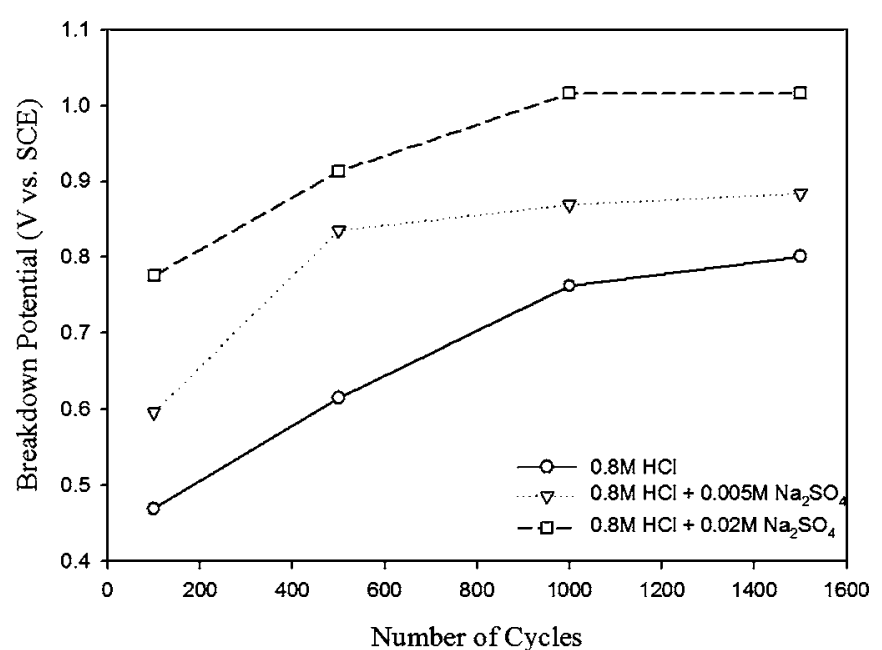

Figure 8. Breakdown potential as a function of the number of etching cycles.

potential notably increased with the concentration of sulfate ions regardless of the number of etching cycles. This dependence agrees well with those reported. ${ }^{6,7}$

$X$-ray photoelectron spectroscopy $(X P S)$ - - General survey XPS spectra identified aluminum and oxygen species as the main constituents of the surface film (not shown here). High-resolution scans of XPS further revealed the existence of sulfur and chlorine species on the surface film, as shown in Fig. 9a and b. Furthermore, the S $2 p$ and $\mathrm{Cl} 2 \mathrm{p}$ binding energy appeared at approximately 169.4 and $198.5 \mathrm{eV}$, respectively, indicating the presence of sulfate and chloride. ${ }^{25}$ Figure 9 also shows that the amount of sulfate in the surface film increased while that of chloride decreased when more sulfate ions were added to the solution.

\section{Discussion}

Effects of sulfate ions. - Commercial aluminum foils for lowvoltage electrolytic capacitor are generally fabricated by ac etching. After proper etching, the foil was composed of a pitted structure on both sides and an unetched aluminum core in the center, while retaining its original thickness before etching. ${ }^{3,5}$ To achieve this ideal structure, the loss of unetched aluminum due to undermining by the pits must be suppressed to the least extent. The solution containing hydrochloric acid as the sole constituent is apparently not suitable for etching aluminum to have enough pitted depth and effective areas without the reduction in thickness. ${ }^{3}$ This reduction in thickness is a result of the merge of strings of cubic pits, and the concurrent loss of unattacked aluminum (Fig. 2). Sulfate ions in hydrochloric acid can suppress undermining of aluminum by inhibiting the formation of strings of cubic pits (Fig. 3).

The presence of sulfate ions in hydrochloric acid results in a higher breakdown potential (Fig. 8) and passivation of the newly formed pits as an indicator of the constant potential when the breakdown potential is reached (Fig. 7). Sulfate ions adsorbed on the foil surface (Fig. 9) must play an important role in the nucleation and subsequent passivation of etch pits. Besides, the film characteristic of thin anodic film (Fig. 3b) directly contacting aluminum suggests that sulfate ions in hydrochloric acid enhance the formation of anodic film on aluminum before the breakdown potential is reached during the anodic half-cycle. ${ }^{7}$ Interestingly, sulfate ions in acid solutions have long been used for anodizing aluminum to form aluminum oxide. ${ }^{26}$

Another striking effect of sulfate ions is to reduce the fraction of the relatively flat area dotted with scattered fine pits (Fig. 1). Etch films have been observed on aluminum etched in hydrochloric or nitric acid with the ac current, and have been considered to form
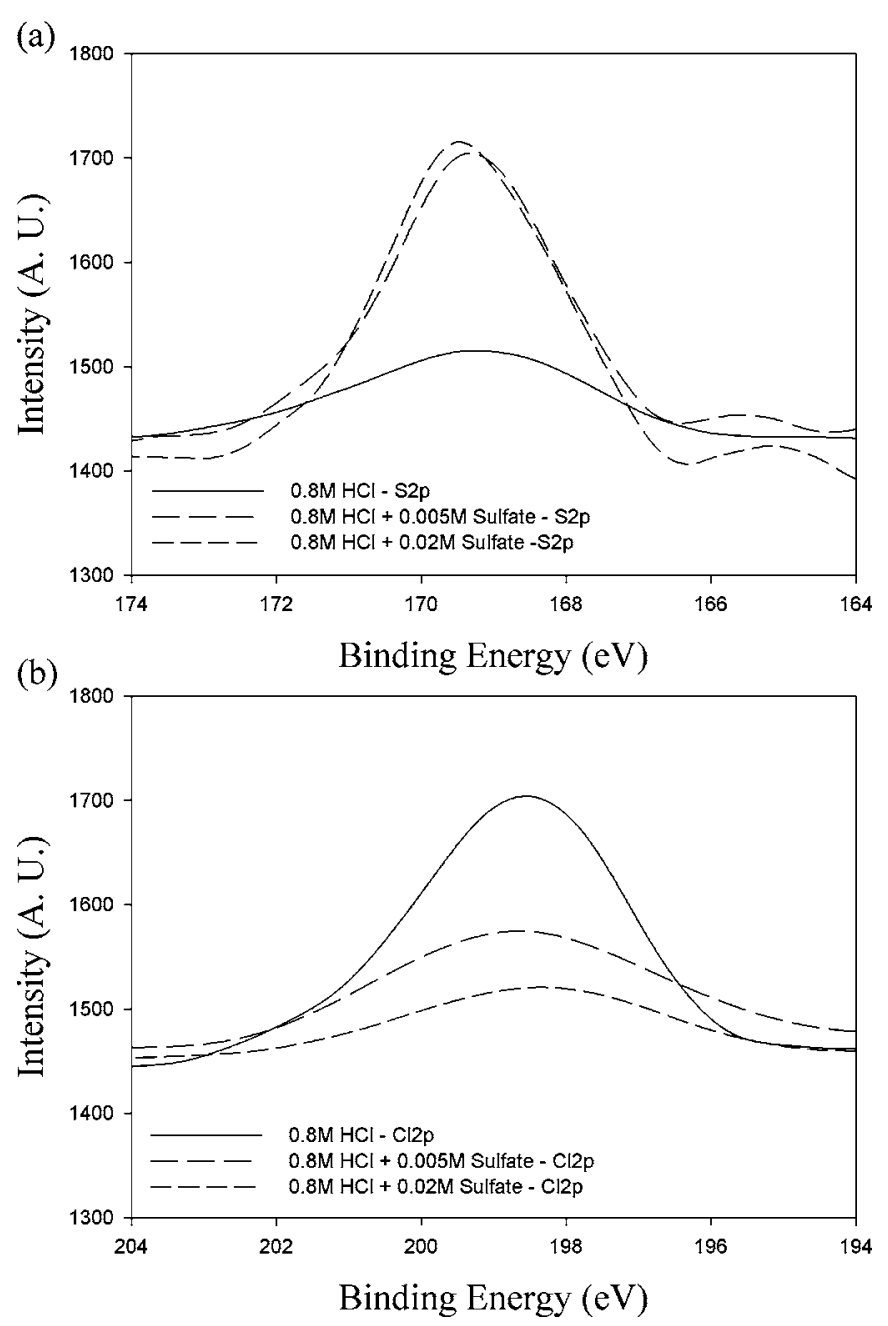

Figure 9. High-resolution scans of XPS for (a) S 2p and (b) $\mathrm{Cl} 2 \mathrm{p}$.

during the cathodic half-cycle. ${ }^{1,2,22-24}$ During the subsequent anodic half-cycle, new pits form locally on the aluminum surface or inside the preexisting pits that have been passivated by the etch film. In the presence of chloride ions, new pits inside the preexisting pit nucleate on the weak spots of the etch film ${ }^{1,2}$ that are attacked by chloride ions with the assistance of positive potential. As passivation of the preexisting pits is promoted by the adsorbed sulfate ions, probably due to competitive adsorption of sulfate ions with chloride ions and to the formation of aluminum sulfate or anodized film, the aluminum surface can be attacked to a larger extent in the solution with sulfate ions than in that without sulfate ions. As a result, the foil etched in hydrochloric acid with sulfate ions contained less relatively flat areas than that etched in the solution without sulfate ions, signifying a more uniformly etched surface in the solution with sulfate ions (Fig. 1).

Pit nucleation and propagation.- Aluminum etched in chloride-containing solutions with the dc or ac current contains cubic pits characteristic of the attack on $\{100\}$ crystallographic planes. ${ }^{2,22-24,27-30}$ The cubic pit formed during dc etching propagates along the tip of the pit while leaving the four sidewalls passive, thus resulting in tunnel pit. Pulsed reductions of the anodic etching current of several milliseconds duration bring about passivation of the active pit tip, while tunnel growth continues after the resumption of the current. ${ }^{28}$ Variation in current results in a change in the active area of the pit tip, ${ }^{29}$ but hardly deviates the tunnel from its straight 
axis. ${ }^{30}$ Unlike dc etching, ac etching involves cathodic half-cycles, during which the sidewalls and base of the cubic pit can be passivated by the etch film.

Consequently, tunnel pits are hardly observed during ac etching. Instead, new pits nucleate randomly inside the preexisting pit during the subsequent anodic half-cycle, ${ }^{3}$ thus leading to the formation of high-density cubic pits (see Fig. 10 in Ref. 2). Nevertheless, the base of the pit, if not completely passivated by the etch film, can be the preferential site to be attacked during the anodic half-cycle because that current step or ramp of the dc current hardly causes deviation of the tunnel from its straight axis. ${ }^{30}$ Consequently, strings of cubic pits are frequently observed (see Fig. 3 in Ref. 3, also Fig. 2 in the present study).

Undermining of aluminum by strings of cubic pits formed in hydrochloric acid without sulfate ions promotes the formation of V-shaped structure, and even worse, results in the loss of unattacked aluminum.

Adsorbed on the sidewalls and base of the cubic pit, sulfate ions in hydrochloric acid can enhance passivation of the pit. This reduces the difference in the stability between the sidewalls and base of the cubic pit and hence equalizes, to some extent, the opportunity for the nucleation of new pits on sidewalls and base of the existing pit. Consequently, most of the pits grow laterally and inward, which, in turn, favors the formation of U-shaped pitted structure (Fig. 5). This significantly reduces the risk of the loss of aluminum due to undermining of strings of cubic pits.

As the pits grow with continued etching, the solution inside the existing pits will be depleted of protons but enriched with aluminum ions, because the former is reduced during the cathodic half-cycle while the latter is created during the anodic half-cycle. As a result hydrated alumina, aluminum chloride, and sulfate precipitate more readily inside the existing occluded pit, giving a rise in the breakdown potential (Fig. 8).

\section{Conclusions}

The effects of sulfate ions in hydrochloric acid on pitting behavior of aluminum foil during ac etching have been investigated. Results in this study can be summarized as follows:

1. After ac etching in hydrochloric acid with and without sulfate ions, the surface of aluminum contained pitted areas and relatively flat areas. The fraction of the relatively flat areas decreased with increasing concentration of sulfate ions in hydrochloric acid.

2. Cubic pits were the building element of the pitted structure on aluminum etched with the ac current in hydrochloric acid with and without sulfate ions.

3. Two overall pitted morphologies resulting from the merge of the individual cubic pits were observed: V-shaped and U-shaped pitted structures. Adding sulfate ions in hydrochloric acid increased the ratio of U-shaped to $\mathrm{V}$-shaped structures.

4. Undermining of aluminum by strings of cubic pits was more frequently observed in the solution without sulfate ions. The reduction in the weight loss by the presence of sulfate ions seems to be due to the suppression of the formation of strings of cubic pits via adsorption of sulfate ions on the sidewalls and base of the cubic pit

5. The presence of sulfate ions in hydrochloric acid increased the breakdown potential and also promoted repassivation of the pits. Moreover, the breakdown potential increased with continued etching because the occluded pits were gradually enriched with aluminum ions, but depleted of protons.

\section{Acknowledgments}

The authors thank the National Science Council of the Republic of China for financially supporting this research under grant no. 932216E002020. L. C. Wang, National Sun Yat-sen University, is acknowledged for her assistance with the TEM work. This study made use of the Electron Microscopes of National Taiwan University and National Sun Yat-sen University, supported by the National Science Council, Republic of China.

National Taiwan University assisted in meeting the publication costs of this article.

\section{References}

1. G. E. Thompson and G. C. Wood, Corros. Sci., 18, 721 (1978).

2. C. K. Dyer and R. S. Alwitt, J. Electrochem. Soc., 128, 300 (1981).

3. H. J. de Wit and H. M. J. Boots, J. Appl. Phys., 54, 2727 (1983).

4. K. Vu Quang, F. Brindel, G. Laslaz, and R. Buttoudin, J. Electrochem. Soc., 130, 1248 (1983).

5. W. M. Moore, C. T. Chen, and G. A. Shirn, Corrosion (Houston), 40, 644 (1984).

6. E. Suganuma, Y. Tanno, M. Nakano, and I. Umetsu, Jpn. J. Surf. Technol., 49, 643 (1998).

7. J. H. Jeong, S. S. Kim, H. G. Kim, C. H. Choi, and D. N. Lee, Mater. Sci. Forum, 217-222, 1565 (1996).

8. T. H. Nguyen and C. E. Hutchins, US Pat. 4,588,486 (1986).

9. C. E. Hutchins, D. E. Rougean, T. E. Chalmers, and R. A. Bemis, US Pat. 4,584,067 (1986).

10. A. J. Dowell, Trans. Inst. Met. Finish., 57, 138 (1979).

11. P. Laevers, H. Terryn, J. Vereecken, B. Kernig, and B. Grzemba, Corros. Sci., 38, 413 (1996).

12. M. S. Hunter, J. Electrochem. Soc., 117, 1215 (1970).

13. C. G. Dunn, R. B. Bolon, A. S. Alwan, and A. W. Stirling, J. Electrochem. Soc., 118, 381 (1971)

14. J. Flis and L. Kowalczyk, J. Appl. Electrochem., 25, 501 (1995)

15. W. J. Lee and S. I. Pyun, Electrochim. Acta, 45, 1901 (2000)

16. H. Bohni and H. H. Uhlig, J. Electrochem. Soc., 116, 906 (1969).

17. F. Hunkeler and H. Bohni, Werkst. Korros, 34, 68 (1983).

18. Z. Szklarska-Smialowska, Pitting Corrosion of Metals, 1st ed., National Association of Corrosion Engineers, Houston (1986).

19. T. I. Wu and J. K. Wu, Corrosion (Houston), 51, 185 (1995)

20. S. Kuroda and K. Tohma, Jpn. J. Light Met., 48, 288 (1998).

21. E. McCafferty, Corros. Sci., 45, 1421 (2003).

22. H. Terryn, J. Vereecken, and G. E. Thompson, Trans. Inst. Met. Finish., 66, 116 (1988).

23. P. Laevers, H. Terryn, J. Vereecken, and G. E. Thompson, Corros. Sci., 35, 231 (1993).

24. C. S. Lin and H. M. Fu, J. Electrochem. Soc., 148, 240 (2001).

25. J. F. Moulder, W. F. Stickle, P. E. Sobol, and K. D. Bomben, Handbook of X-Ray Photoelectron Spectroscopy, Perkin-Elmer, Eden Prairie, MN (1992).

26. T. Biestek and J. Weber, Electrolytic and Chemical Conversion Coatings, 1st ed., Portcullis Press Ltd., Redhill, Surrey, U.K. (1976).

27. C. G. Dunn and R. B. Bolon, J. Electrochem. Soc., 116, 1050 (1969).

28. B. J. Wiersma, Y. Tak, and K. R. Hebert, J. Electrochem. Soc., 138, 371 (1991).

29. R. S. Alwitt, H. Uchi, T. R. Beck, and R. C. Alkire, J. Electrochem. Soc., 131, 13 (1984).

30. K. Hebert and R. Alkire, J. Electrochem. Soc., 135, 2146 (1988). 